The experimental work clescribed in this paper was carried out by the junior author at the University of Rochester, $N$. Y., and at the Johns Hopkins University, during the session fgo 7 - i.

Mcmaster Univirity, Toronto, canain,

September, rgos.

\title{
INTRAMOLECULAR REARRANGEMENT OF PHTHALAMIDIC ACIDS. III.
}

BY J. BISHOP TINGLE AND H. F. ROLKER,

Received October $\pi$, ryos.

The previous papers ${ }^{1}$ on this subject described the formation of phthalphenylimide, $\mathrm{C}_{0} \mathrm{H}_{4} \backslash{ }_{\mathrm{CO}}^{\mathrm{CO}}>\mathrm{NC}_{6} \mathrm{H}_{5}$, from phthalphenylamidic (phthalanilic) acid, at a temperature about $100^{\circ}$ below its melting point, in presence of aniline. The fact that tertiary bases behave like aniline, led to the suggestion being made that the dehydration is due to salt formation. It was also shown that certain other phthalamidic acids behave in a similar manner, but not in an identical one. In the present communication we give an account of further work which we have done on this subject during the past year.

We have employed the following acids: phthalphenylamidic, $\mathrm{C}_{8} \mathrm{H}_{5} \mathrm{NHCOC}_{6} \mathrm{H}_{4} \mathrm{CO}_{2} \mathrm{H}$; phthalortho-, meta- and paratolylamidic, $\mathrm{CH}_{3} \mathrm{C}_{6} \mathrm{H}_{4} \mathrm{NHCOC}_{6} \mathrm{H}_{4} \mathrm{CO}_{2} \mathrm{H}$; phthalmeta- and paranitrophenylamidic, $\mathrm{O}_{2} \mathrm{NC}_{6} \mathrm{H}_{4} \mathrm{NHCOC}_{6} \mathrm{H}_{4} \mathrm{CO}_{2} \mathrm{H}$; and phthal- $\alpha-$ and $\beta$-naphthylamidic, $\mathrm{C}_{10} \mathrm{H}_{7} \mathrm{NHCOC}_{6} \mathrm{H}_{4} \mathrm{CO}_{2} \mathrm{H}$. The two nitro acids and the neta- and paratolyl acids have not been obtained previously.

As we required relatively large quantities of these acids we have worked out the details of their preparation and purification with care. Our method is described later in this paper (p. I885). It is very much simpler and more expeditious than the older process, but does not differ from it in general principles.

In the experiments recorcled in the earlier papers the acid and base were generally heated $2^{1 / 2}$ hours, or longer. In this later work we usually limited the time to 35 minutes because we wished to avoid the complete transformation of the acid into the imide. In this way we have been able to isolate certain intermediate products and have also succeeded, in some cases, in determining the relative velocity with which the various imides are formed.

We have investigated the effect of the following amines on the acids mentioned above: Pyridine, quinoline, ethylaniline, diphenylamine, aniline, $\alpha$-and $\beta$-naphthylamine and, in most cases, of benzylamine. In

${ }^{1}$ Bishop Tingle and Cram, Am. Chem. J., 37, 596 (1907); Bishop Tingle and Lovelace, Ibid., 38, 642 (1907). 
addition we used, with each acid, the particular amine from which it is derived. It will be convenient to discuss the results in the order given.

PYRIDINE.-This substance reacted with all the acids which we investigated, forming, in each case, the substituted imide corresponding to the original acid. The reaction is relatively slow, but experiments described in an earlier paper showed that the change is complete, if sufficient time be allowed. With the phthal-p-nitrophenylamidic acid a salt of pyridine appears to be formed in addition to the imide.

The action of QUiNOLINE resembles that of pyridine very closely, but it is, on the whole, slightly slower. It also forms a salt with the acid mentioned.

ETHYI,ANIIINE; behaves essentially like pyridine. It gave, with each acid, the corresponding imide. Under the conditions which we employed phthal- $\beta$-naphthylamidic acid failed to react and the $\alpha$-naphthyl acid was transformed very slowly. In general, the use of this amine offers no advantages over that of pyridine.

With DIPHENYLAMINE a very small quantity of phthal-p-tolyl- and $\alpha$-naphthylimides were obtained from the corresponding acids, after Io and 5 hours' heating, respectively. It is practically certain that the prolonged heating is alone responsible for this slight degree of transformation. All the remaining acids were recovered unchanged.

ANILINE yields, with each acid, phthalphenylimide; in addition it gave some phthalphenylamidic acid with each of the three tolylamidic acids, and, in the case of the para acid, some phthalphenyl-p-tolyldiamide. The reaction with phthal- $\beta$-naphthylamidic acid is very slow, even at $100^{\circ}$.

$\alpha$-NAFHTHyLAmine produced no change with either the $\alpha$ - or the $\beta$ naphthyl-nor with the $p$-nitrophenylamidic acids. With all the remaining compounds it gave phthal- $\alpha$-naphthylamidic acid mixed, in two cases, with phthal- $m$-tolyl- and - $p$-tolylimide, respectively. A comparison of these results with those obtained by the use of aniline shows that the phenyl and naphthyl groups are mutually replaceable in the system $\mathrm{RNH}_{2} \rightleftarrows \mathrm{R}^{\prime} \mathrm{NHCOC}_{6} \mathrm{H}_{4} \mathrm{CO}_{2} \mathrm{H}$. The velocity appears to be greatest when $\mathrm{R}=\mathrm{C}_{10} \mathrm{H}_{7}$.

$\beta$-NAPHTHYL.LMINE gave phthal- $\beta$-naphthylamidic acid in all cases, but with the $p$-nitrophenylamidic acid it was necessary to prolong the experiment for 5 hours. Under these circumstances it is almost certain that $\alpha$-naphthylamine would have also reacted with the acid in question. In the case of the $m$-nitrophenylamidic acid some phthal-m-nitrophenylimide was formed. Essentially, therefore, both the naphthylamines act in the same way.

ORTHO-, META- AND PARATOLUIDINE were each treated only with that particular phthalamidic acid yielded by the individual amine. The product consisted of phthal-o-, $m$-, or $p$-tolylimide, respectively, together 
with nuchanged acid. The eflicion of these andines in producing their respective inides is deciledly inferior to that of quinoline, pyridine and ethylaniline.

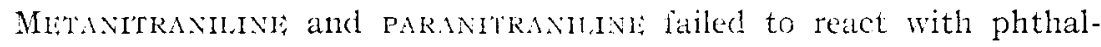
$m$ - and $p$-nitrophenylamidic acids, respectively. In the former case heating was continued for 5 hours at $100^{\circ}$.

BENZYhMINI gives the greatest complications which we have hitherto encountered, and our experiments with it are not yet completed. It appears to form salts with the following acids: phthal-m-tolyl-, $m$-ritrophenvl and 3 -naphthylamidic acids. With the second of these acids it also gives some phthaldibenzyldianide, which is also produced from phthal-a-naphthylamidic acid. In addition to the salt mentioned above, phthal-j-naphthylamidic acid yields at least one, and possibly several other connpounds with benzylamine, which are at present under investigation. Iirom the a-naphthylamidic acid we also obtained what appears to be an orthe ralt, $\mathrm{C}_{6 i} \mathrm{H}_{60} \mathrm{CH}_{2} \mathrm{NH}\left(\mathrm{C}_{20} \mathrm{H}_{7} \mathrm{NHCC}(\mathrm{OH})_{60} \mathrm{H}_{4} \mathrm{CONHIC}_{10} \mathrm{H}_{7}\right.$.

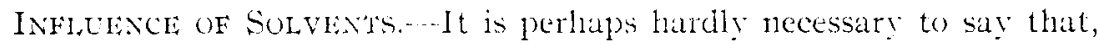
in all cases, blank experiments were marle with each acid, in order to demonstrate that the temperatures and solvents cmployed were in thenselves insufficient to cause the formation of imicles. The larger number of experiments, in this connection, were carried ont with phthalpheny. amidic acid. In alcohol ( 95 per cent.) the change to phenylinicle is conn plete after 45 minutes, at $103^{\circ}$. Aiter 3.5 minutes, at $05^{\circ}, 9$ per cent. of the acid had been transformed. Inder similar conclitions, in acetone, only I.5 per cent. of the acid reacted, whereas in ether, benzene and tolutene there was no change.

These results, together with those deseribed in the earlier papers, show that the change of the phthalamidic acids into phthalimides, $\left.\mathrm{RNHCOC}_{6} \mathrm{H}_{4} \mathrm{CO}\right)_{3} \mathrm{H}$ $\rightarrow \mathrm{C}_{0} \mathrm{H}_{4} \backslash \mathrm{CO}>\mathrm{NR}+\mathrm{H}_{2} \mathrm{O}$, is dependent on the following factors:

(I) The nature of the group $R$; apparently the stability of the acid increases as $R$ becomes more negative. (2) The temperature; increase of this of course facilitates the transiomation. (3) The nature of the amine. The effect of individtal amines is discussed in the preceding pages; in general, it appears that an anine is the more active the more strongly positive it is. (4) The nature of the solvent. Alcohol (95 per cent.) is in many cases active in producing the change.

The suggestion was made in an earlier paper that, in so far as it is not produced by the eliect of temperature alone, the nechanism of the transformation of amidic acid to imide is dependent on the formation of a salt. The results described in the present commnnication amply confirm this hypothesis. The active influence of aleohol is surprising. Ibsolute 
alcohol is, of course, a "dehydrating agent," but the attraction of 95 per cent. alcohol for water is not great. We venture to think that the identity of effect produced by alcohol and amines is due to a common cause, namely to salt formation. Stieglitz and his students have shown ${ }^{1}$ that the "catalytic effect" of mineral acids in promoting the preparation of esters of organic acids is due to the production of an oxonium salt of the mineral acid and the alcohol.

We believe that this conception of salt formation preceding dehydration can be extended with profit, not only to the very numerous condensations produced by the action of small quantities of tertiary bases, alkali hydroxides or ethylates, conc. acids, etc., but also to dehydrations effected by such substances as zinc chloride. It is quite inpossible to regard them intelligently without the help of some such mechanism.

\section{Experimental.}

The experiments were usually carried out as follows: A gram of the acid under investigation was mixed with two molecular proportions of the base. If a solvent was employed it was then added and the mixture heated to the desired temperature in a large jacketed water bath, the contents of which were stirred rapidly with the help of an electric motor. In addition, a thermo-regulator was employed. There was no difficulty in maintaining the temperatures constant to within $0.5^{\circ}$, which was amply sufficient for our purpose. In some experiments the solvent was allowed to evaporate, in others it was retained by a reflux condenser.

Solvents.-The solvents employed were usually benzene or toluene. In some cases alcohol (95 per cent.) was used and occasionally petroleum ether or ligroin. In all cases special tests were made in order to prove that, in the absence of a base, the particular acid under examination was not affected by the solvent and temperature employed.

Preparation of Materials.-The phthalamidic acids used in this investigation were obtained by the general methods described in the literature. We have, however, introduced a number of simplifications in detail which make the preparation of the acids a matter of great ease. The purity of our products was always equal to that of the specimens obtained by other chemists who employed more complicated methods. In some cases, indeed, as shown by their melting points, our preparations were superior to any hitherto described.

Phthalic acid, or its anhydride (I.I mols.), was mixed with the amine (I mol.) and heated with a direct flame to $200^{\circ}$, or to the boiling point of the imine, whichever was the lower. After 5-1o minutes and when steam had ceased to be evolved, the molten material was poured into a dish

'Report Cong. Arts and Sci. St. Louis, IV, p. 276 (1904); Am. Chem. J., 38, 743 (1907). Numerous other papers by Stieglitz's students appeared subsequently in the same Journal. 
which was turned so that the liquid solidified in a thin layer. When sufficiently cool aqueons sodium hydroxide (Io per cent.) was added and the dish heated on the water hath, with frequent stirring.

When the imicle alnost ceases to dissolve, after about an hour, the alkaline liquid is filtered hot and acidified with dilute hydrochloric acis. The residual imide is treated in succession with three or four other portions of sodium lydroxide, which are added to the first extract.

'The precipitated anidic acid is filtered off, washed repeatedly with cold water and dried on a porous plate. In this condition it is usually sulficiently pure for experimental purposes. We demonstrated this point by special tests. In some instances it was purified by solution in aqueons sodium carbonate, Hydrolysis of the imides by alcoholic alkali and the purilication of the anidic acids by means of their calcium salts are quite unnecessary. The aqueous solutions of hydrochloric acid and of sodium hydroxicle were sufficiently dilute to insure the removal of the smiall quantities of phthalic acid and of amine which had escaped combination. our yieids of imides and of amidic acids were practically quantitative. The products of the reactions were identified by mixed melting points and by analysis, but in most cases it has not been considered necessary to gire the details. In the experiments described below the amidic acicl or acids present in the product of the reaction was separated without difficulty by means of aqueous sodium carbonate solution; free annines were extracted with dilute hydrochloric acid and the residual neutral products (imides or amides) were isolated by solution in various organic solvents.

I. Expcriments with Phthalphenylamidic Acid (Phthalanilic Acid), $C_{6} H_{5} N H C O C_{6} H_{1} C()_{2} H .--$ When heated alone at its melting point, $166.5^{\circ}$, this acid is, of course, converted conpletely into the phenylimide. The same change takes place quantitatively after 45 minutes, at $I\left(0^{\circ}\right.$; in the presence of alcohol (9.5 per cent.) at $65^{\circ}$, in a sealed tube, about () per cent. of the acid had reacted after 3.5 minutes.

With acetone the quantity of phenylimide formed was only about I.5 per cent., under similar conditions, and ether, benzene and toluene failed to produce any change. In presence of pyriline or quinoline about 25 per cent. of the acid is transformed into the phenylimide, after 3.5 minutes' heating, at $65^{\circ}$.

Aniline is practically without action on the acid in toluene solution, at $100^{\circ}$, during 3.5 minutes. Other experiments with aniline have been described in the earlier papers on this subject.

At $100^{\circ}, \alpha$ and $\beta$-naphthalamines, convert the acid into the respective naphthylumiclic acids. After 35 minutes the oramine had transformed

${ }^{1}$ Loc. cit. 
about 70 per cent. of the original acid, whereas the $\beta$-amine had only reacted with about 30 per cent. after 45 minutes.

Ethylaniline converts about I 5 per cent. of the acid into the phenylimide, at $100^{\circ}$, after 45 minutes. At lower temperatures it is without action.

Diphenylamine fails to react with the acid, at $100^{\circ}$, after 35 minutes.

II. Experiments with phthal-o-tolylamidic Acid, $\mathrm{CH}_{3} \mathrm{C}_{6} \mathrm{H}_{4} \mathrm{NHCOC}_{6} \mathrm{H}_{4} \mathrm{CO}_{2} \mathrm{H}$. - The acid employed in our experiments melted at $166-1(1) 7^{\circ}$; it was prepared directly from the imide, without special purification, and failed to react with benzene after 35 minutes at $100^{\circ}$. Unless otherwise stated the time of heating was 35 minutes in the experiments described below; at $65^{\circ}$ pyridine and quinoline each yielded a quantity of the $o$-tolylimide, together with unchanged acid. From $\alpha$-and $\beta$-naphthylamines the respective $\alpha$ - and $\beta$-naphthylamidic acids were obtained, mixed with the original acid; the change of the latter was complete in the case of the $\alpha$-amine, at $100^{\circ}$.

Aniline, at $65^{\circ}$, converts the 0 -tolyl acid completely into a mixture of phthalphenylamidic acid and its imide.

With o-toluidine there is no action at $65^{\circ}$, but at $100^{\circ}$ the transformation into the o-tolylimide is complete.

Ethylaniline, at $65^{\circ}$, yields a mixture of unchanged acid and o-tolylimide.

Diphenylamine fails to react even after 5 hours, at $100^{\circ}$, in presence of benzene.

III. Experiments with phthal-m-tolylamidic Acid.-This compound does not appear to have been prepared hitherto. It was obtained without difficulty, according to the general method described above, and was purified by means of its sodium salt. The acid crystallizes from benzene in needles, from alcohol in flat plates and melts at $159-16 I^{\circ}$. It is very sparingly soluble in benzene, carbon tetrachloride and chloroform, more readily in alcohol ( 95 per cent.) and dissolves very easily in nitrobenzene. In benzene the acid is not preceptibly changed after 35 minutes' heating at $65^{\circ}$, but after the same interval, at $100^{\circ}$, in alcohol, about ro per cent. of it is converted into phthal-m-tolylimide. This latter compound melts at $170-172^{\circ}$, not $153^{\circ}$ as stated by Frohlich. ${ }^{1}$

In the experiments described below the acid was heated at $65^{\circ}$, during 35 minutes.

Pyridine ( 3.24 grams) was mixed with the acid (2 grams), no solvent being employed. Only about 15 per cent. of the acid was transformed into the imide.

With quinoline (4 grams) the change was even less complete, only about

1 Ber., I7, 2679. 
Io per cent. of purified imide being obtained. The remaining bases were used in benzene solution.

Aniline gives a mixture of phthalphenylamidic acid and phthalphenyinide, together with some of the unchanged original acid.

m-Toluidine converts about 1 per cent. of the acid into the $m$-tolylinide.

With a-naphthylamine we obtained a very small quantity of the $m$-tolytimidl. About 65 per cent. of the acid was, however, transformed into phthal-conaphthylamidic acid.

3. Vaphthylamine gave, as the only tangible product, phthal-\%-naphthyamiclic acid, but a very small quantity of the tolylimide may have been formed also.

There is a considerable evolution of heat when benzylamine is mixed with the tolylamidic acid. The prinary product is bonzylammonium phthal-m-tolylamidate, $\mathrm{MeC}_{6} \mathrm{H}_{1} \mathrm{NHCOC}_{6} \mathrm{H}_{1} \mathrm{CO}_{2} \mathrm{NH}_{3} \mathrm{CH}_{2} \mathrm{C}_{6} \mathrm{H}_{5}$. It crystallizes from 95 per cent. alcohol and melts at $157^{\circ}$. When mixed with an equal quantity of the original acid (m.p. $159^{-1} 11^{\circ}$ ) the melting point is $122-126^{\circ}$. The salt is soluble in xylene, but not in benzene. With aqueous sodium carbonate solution benzylamine is liberated and the original acid regenerated. At its melting point the salt also evolves some benzylanine; the residue consists essentially of phthalbenzylimide, m. p. $116^{\circ}$. Analysis:

C.......... found 72.54 , calculated 72.82

H.......... found 6.73 , calculated 6.08

Iixcept in presence of excess of the base the compound is somewhat unstable. The bearing which this salt has on our theory of the mechanism of the transformation of the phthalamidic acids is discussed in the first part of this communication.

Ethylaniline converts a portion of the acid into the m-tolylimide, the remainder being recovered unchanged.

In benzene solution diphonglumine fails to react with the acid even after 5 hours' heating, at $100^{\circ}$.

I1. Experiments with Phthal-p-tolylamidic Acil---This acid appears not to have been obtained previously. It was prepared from the $p$ tolylimide in the manner described above. It crystallizes from alcohol (40 per cent.) in glistening white flakes, melting at $160^{\circ}$. At the boiling point it dissolves very readily in nitrobenzene, more sparingly in toluene and is soluble with difficulty in benzene. Phthal-p-tolylimide (m. p. $201-202^{\circ}$ ) dissolves in benzene with great ease. In the following ex. periments the period of heating was 35 mintues. At $100^{\circ}$, in presence of alcohol $(95$ per cent.) and of nitrobenzene, respectively, about 30 per cent. of the acid is converted into the tolylinide, where as with toluene as solvent the whole of the acid was recovered unchanged. It slould be pointed ont that the nitrobenzene solution, after the prescribed interval of heating, was evaporated on the water bath; consequently, in the ex- 
periment in question, the acid was exposed to a temperature of approximately $100^{\circ}$ for a very considerable length of time.

The tests with the bases mentioned below were carried out at $65^{\circ}$, the period of heating being, as stated, 35 minutes.

Pyridine, in excess, without a solvent, gave about 37 per cent. of $p$ tolylimide.

With quinoline, under similar conditions, only about 20 per cent. of the $p$-tolylimide is produced.

The interaction of aniline and the acid is somewhat complicated and we have not yet worked it out fully. The chief products appear to be phthalphenylamidic acid, the phenylimide, possibly some $p$-tolylimide and a compound which crystallizes from benzene and also from methyl alcohol, and melts sharply at $168^{\circ}$. The analytical results indicate that this substance is phthalphenyl-p-tolyldiamide, $\mathrm{C}_{6} \mathrm{H}_{5} \mathrm{NHCOC}_{6} \mathrm{H}_{4} \mathrm{CONHC}_{6} \mathrm{H}_{4} \mathrm{CH}_{3}$; it is now under investigation.

$p$-Toluidine is without action on the acid under the conditions mentioned, but the transformation to $p$-tolylimide is complete after 5 hours, at $100^{\circ}$.

From $\alpha$-naphthylamine we obtained a mixture of phthal- $\alpha$-naphthylamidic acid and phthal-p-tolylimide.

The only product which we isolated by the action of $\beta$-naphthylamine was phthal- $\beta$-naphthylamidic acid.

Ethylaniline yielded the $p$-tolylimide, about 43 per cent., together with unchanged acid.

After 5 hours' heating, at $100^{\circ}$, in presence of benzene, diphenylamine failed to react with the acid, but after Io hours at the same temperature the acid was converted completely into the $p$-tolylimide. The action of the amine is, therefore, practically negligible, because the transformation is undoubtedly caused by the prolonged heating.

$V$. Experiments with Phthal-m-Nitrophenylamidic Acid.-We have failed to find any description of this acid. It was prepared without difficulty by hydrolyzing the imide with aqueous solution of sodium hydroxide. After purification it was deposited from alcohol (40 per cent.) as a light yellow powder, melting at $202^{\circ}$. It dissolves very readily in a cold aqueous solution of sodium carbonate.

In the experiments described below the time of heating was 35 minutes, unless otherwise stated.

At $65^{\circ}$, in benzene, pyridine is practically without action on the acid, but at $100^{\circ}$, under similar conditions, about ro per cent. of phthal-mnitrophenylimide is produced.

There is a considerable evolution of heat when the acid is mixed with quinoline; at $100^{\circ}$, in presence of a little benzene, we obtained about I.5 per cent. of the $m$-nitrophenylimide, a quantity of unchanged acid, which was removed by treatment with cold, dilute, aqueous solution of 
sodium carbonate and a new compound. This crystallizes from methyl alcohol, or from acetone on the addition of gasoline, in long, highly lustrous, silky fibres. It melts sharply at $151^{\circ}$, then solidifies and melts again at $210^{\circ}$. Warm aqueous solution of sodium carbonate regenerates quinoline and the original acid, which was fully identified. There can be little doubt, therefore, that the substance is quinolinium phthal-mnitrophonylamidate, $\mathrm{O}_{3.2} \mathrm{NC}_{6} \mathrm{H}_{4} \mathrm{NHCOC}_{6} \mathrm{H}_{4} \mathrm{CO}_{2} \mathrm{NHC}_{3} \mathrm{H}_{7}$, closely concordant analytical results do not agree with this formula but rather with $\mathrm{C}_{22} \mathrm{H}_{17} \mathrm{O}_{3} \mathrm{~N}_{3}$. Considering the nature of these compounds and the difficulty of purifying them without some decomposition taking place, we believe that the experimental evidence is much stronger proof of their nature than the analytical data.

Aniline is practically without action on the acid after 35 minutes, at $65^{\circ}$, in presence of benzene, but at $100^{\circ}$, under similar conditions, about 31 per cent. of the phenylinide is produced. In another experiment the acid was heated during 4 hours, at $100^{\circ}$, with 7.5 parts of aniline, no solvent being employed. The yield of phenylimide was 45 per cent. of the acid employed.

$m$-Nitraniline does not appear to react with the acid, in presence of benzene, even after 5 hours' heating at $100^{\circ}$. Both the amine and the acid were recovered and identified.

Benzylamine and the acid, after 35 minutes, at $100^{\circ}$, yieid phthaldibenzyldianide (m. p. $178^{\circ}$ ) together with benzylammonium phthal-mnitrophenylamidate, $\mathrm{O}_{2} \mathrm{NC}_{6} \mathrm{H}_{1} \mathrm{NH} \mathrm{COC}_{6} \mathrm{H}_{4} \mathrm{CO}_{2} \mathrm{NH}_{3} \mathrm{CH}_{2} \mathrm{C}_{6} \mathrm{H}_{5}$, which is separated by its greater solubility in alcohol. The salt is prepared more conveniently by mixing the acid with a slight excess of the amine. There is a considerable evolution of heat: when cold the product is recrystallized from methyl alcohol and is deposited in small, light yellow, flat, rectangular plates, melting at $168^{\circ}$. No diamide is formed under these conditions. When digested with aqueous solution of sodiun carbonate the salt regenerates benzylamine and the original acid. Analysis:

$$
\begin{aligned}
& \text { C............ found } 64.90 \text {, calculated } 64.12 \\
& \mathrm{H} \ldots \ldots \ldots \ldots \ldots \text { found } 5.55 \text {, calculated } 4.83
\end{aligned}
$$

At $100^{\circ}$, after 35 minutes, co-nuphthylaminc converts a portion of the acid into phthal- $\alpha$-naphthylamidic acid. No imicle could be isolated.

B-Naphthylamine, under similar conditions, failed to react, but at $100^{\circ}$, after 5 hours, in presence of benzene, we obtained a mixture of phthal$\beta$-naphthylamidic acid and phthal-m-nitrophenylimide.

Ethyl Aniline fails to react with the acid at $100^{\circ}$, after 35 minutes, but after 5 hours we obtained 4.5 per cent. of the $m$-nitrophenylimide.

Diphenglamine failed to show any action on the acid after 5 hours, at $100^{\circ}$.

VI. Experimonts with Phthal-p-nitrophenylamidic Acid.-This acid 
has not been described previously. It was prepared in the same manner as the meta isomer, which it resembled closely. It was purified by dissolving in a cold, aqueous solution of sodium carbonate and precipitating with hydrochloric acid. It is crystalline and melts at $186^{\circ}$. Experiment showed that the acid is not changed by heating with benzene at $65^{\circ}$, during 35 minutes, consequently the work described below was carried out under these conditions, unless otherwise stated.

Pyridine and the acid yield, chiefly, phthal-p-nitrophenylimide, together with what appears to be a pyridine salt. It is decomposed by solution of sodium carbonate, pyridine being liberated. At $140^{\circ}$, in a capillary tube, it undergoes a change and melts, finally, at $262^{\circ}$, showing that it also has been transformed into the $p$-nitrophenylimide. The quantity of this material which we obtained was too small for further investigation.

A considerable amount of heat is generated when quinoline is added to the acid.

The resulting compound consists of light yellow crystals, melting at $161^{\circ}$. It liberates quinoline when treated with solution of sodium carbonate and, in general properties, resembles the corresponding salt of the phthal-m-nitrophenylamidic acid.

Aniline is without action on the acid under the conditions mentioned, but after 35 minutes' heating at $100^{\circ}$, without a solvent, there was complete conversion into phthalphenylimide.

$p$-Nitraniline failed to react with the acid after 35 minutes, at $100^{\circ}$, in presence of benzene.

Similar results were obtained under these conditions with $\alpha$-naphthylamine and with $\beta$-naphthylamine, but when the latter was heated during 5 hours, at $100^{\circ}$, the acid was converted completely into phthal- $\beta$-naphthylamidic acid.

At $100^{\circ}$, after 35 minutes, in presence of ethylaniline, the acid yielded about 30 per cent. of phthal-p-nitrophenylimide.

Diphenylamine produced no change in the acid after 35 minutes, at $65^{\circ}$.

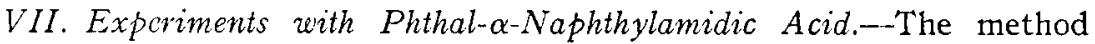
of preparation of this acid described by Piutti ${ }^{1}$ is very inconvenient. It consists in distilling the imide, hydrolyzing with alcoholic potassium hydroxide, then converting the acid into the calcium salt which is eventually purified by recrystallization and subsequently decomposed. This recrystallization of the calcium salt is attended with considerable difficulty; the salt is not very readily soluble in water and when extracted in a Soxhlet apparatus it forms hard, compact masses which are unworkable. We had no difficulty in hydrolyzing the imide with aqueous

${ }^{1}$ Gazz. chim. ital., $15,480$. 
solution of sodium hydroxide and we purified the resulting acid by the method described in the earlier part of this paper (p. 1885). Our preparations of the crude acid melted at $185^{\circ}$, but after purification at $189^{\circ}$. I'iutti ${ }^{1}$ gives the melting point at $185^{\circ}$. Unless otherwise stated the experiments with this acid were made in alcoholic ( 95 per cent.) solution, the time of heating being 35 minutes. At $100^{\circ}, 97$ per cent. of the acid was recovered unchanged.

$1^{\prime} y$ ridine produces but little change at $65^{\circ}$, but at $100^{\circ}$ about 50 per cent. of the acid is transformed into phthal- $\alpha$-naphthylimide.

Quinoline yielded about 8 per cent. of the naphthylimide at $65^{\circ}$, but at $100^{\circ}$ the change into this compound was complete.

After 45 minutes, at $100^{\circ}$, aniline yielded phthalphenylimide, together with unchanged acid. Possibly a little of the naphthylimide may have been formed also, but in quantity too small for identification.

There is a considerable evolution of heat when benzylamine is added to the acid. After heating at $100^{\circ}$ the product consists of unchanged acid and phthaldibenzyldiamide, melting at $174^{-1} 76^{\circ}$. The conversion of the acid into this diamide is almost complete after $1 / 2$ hours, in presence of excess of the base. The only other product which we could detect was a little of the compound described below. It was not obtained in a condition of purity (n, p. $14 \mathrm{I}-144^{\circ}$ ) and when recrystallized twice from alcohol ( 95 per cent.) it appears to be converted into the dibenzylamide.

At $65^{\circ}$, in benzene solution, we obtained only the substance mentioned above (m. p. $14 \mathrm{I}-144^{\circ}$ ), which appears to be an ortho salt. It is deposited from alcohol ( 95 per cent.) in small, granular crystals, melting at I $56-157^{\circ}$. It dissolves in benzene, is precipitated by ligroin and is hydrolyzed very rapidly by slightly warm aqueous solution of sodium carbonate, benzylamine and the original acid being regenerated. Closely agreeing analyses of different preparations indicate that the salt has the formula $\left.\mathrm{C}_{10} \mathrm{H}_{7} \mathrm{NHCOC}{ }_{00} \mathrm{H}_{4} \mathrm{COOH}\right)\left(\mathrm{NHC}_{10} \mathrm{H}_{7}\right) \mathrm{NHCH}_{2} \mathrm{C}_{8} \mathrm{H}_{5}$. We give this formula with reserve for the present.

$$
\begin{aligned}
& \text { C........ found } 80.33 \text { and } 80.23 \text {. } \\
& \text { H....... found } 6.28 \text { and } 6.65 \text {. } \\
& \text { N...... } 7.37 \text { and } 7.5^{2} \text {. }
\end{aligned}
$$

Calculated for $\mathrm{C}_{35} \mathrm{H}_{28} \mathrm{O}_{2} \mathrm{~N}_{3}$ : C 80.45, $\mathrm{H} 5.36, \mathrm{~N} 8.05$ per cent.

This compound is not identical with the substance (m. p. $157^{\circ}$ ) which we obtained from benzylamine and phthal-m-tolylamidic acid. A mixture of the two was found to melt at $138^{\circ}$ (p. I 888 ).

We have already mentioned the difficulty which we have experienced in obtaining satisfactory results by the combustion of compounds of this

${ }^{1}$ Loc. cit. 
class. An attenpt is being made in this laboratory to work out a more satisfactory method for their analysis.

$\alpha$-Naphthylamine exerts no apparent action on the acid after 5 hours' heating, at $100^{\circ}$, in presence of benzene.

Phthal- $\beta$-naphthylamidic acid is the chief product of the reaction of $\beta$-naphthylamine on the $\alpha$-naphthylanidic acid; in addition, we found free $\alpha$-naphthylamine. The experiments were made at $65^{\circ}$, in presence of benzene. Similar results were obtained after 45 minutes, at $100^{\circ}$, in solution of 95 per cent. alcohol.

Ethylaniline is without action at $65^{\circ}$, in benzene, but after 45 minutes, at $100^{\circ}$, in 95 per cent. alcohol, the $\alpha$-naphthylimide was formed, a portion of the acid being recovered.

A little $\alpha$-naphthylimide was produced after heating diphenylamine and the acid in benzene, at $100^{\circ}$, during 5 hours. By far the larger portion of the acid was recovered; consequently the change is probably brought about by the prolonged heating alone, without the participation of the amine.

VIII. Experiments with Phthal- $\beta$-Naphthylamidic Acid-After I I/2 hours' heating, at $100^{\circ}$, in toluene, the acid was recovered unchanged. Unless otherwise stated the experiments described below were carried out under these conditions, except that the time of heating was 35 minutes.

With pyridine about I per cent of $\beta$-naphthylimide was produced.

Quinoline failed to react, but as one of us has shown, ${ }^{1}$ the $\beta$-naphthylimide is formed if the time of heating is sufficiently prolonged.

At $100^{\circ}$ aniline failed to react in benzene, but when the acid was mixed with 3.5 parts of the base, without any solvent, and maintained at $100^{\circ}$ during 5 hours, there was a practically complete transformation into phthalphenylimide.

$\alpha-N a p h t h y l a m i n e$ failed to react after 5 hours, at $100^{\circ}$, in benzene solution.

With $\beta$-naphthylamine we did not detect any reaction at $100^{\circ}$, after 5 hours. The original acid was recovered quantitatively. We were not able to obtain the compound, m. p. $20^{\circ}$, mentioned by Bishop Tingle and Lovelace. ${ }^{2}$ The quantity obtained by them was too small for analysis.

Benzylamine, when mixed with the acid, causes a notable evolution of heat. At least two compounds are formed at $65^{\circ}$. The portion insoluble in ligroin appears to consist of phthaldibenzyldiamide, m. p. I $78-179^{\circ}$. The second substance is a somewhat unstable salt which softens about $148^{\circ}$ and melts about $153^{\circ}$, depending somewhat on the rapidity of the heating. With aqueous solution of sodium carbonate it gives

${ }^{1}$ Bishop Tingle and Lovelace, Am. Chem. J., 38, 649 (1907).

${ }^{2}$ Loc. cit. 
benzylamine and the original acid. Under somewhat different experinental conditions we obtained, apparently, two other compounds melting sharply at $174^{-175^{\circ}}$ and $169^{\circ}$, respectively. The higher melting one is decomposed by aqueous solution of sodium carbonate into the original amine and acid. These compounds are now undergoing further investiga tion in this laboratory by Mr. B. I. Parlett Brenton.

Ethylaniline fails to react with the acid at $100^{\circ}$, after 3.5 minutes, but when the heating is continued during $1 \frac{1}{2}$ hours the conversion into 3-naphthylimide appears to be complete. No solvent was used in this experiment. That the result was due to the influence of the amine is shown by the fact that after 5 hours heating with diphenylaminc, in benzene solution, the whole of the original acid was recovered unchanged.

\section{Summary.}

I. We have prepared a number of new phthalamidic acids, $\mathrm{RNHCOC}_{6} \mathrm{H}_{4} \mathrm{CO}_{2} \mathrm{H}$, and have worked out a simple method by which other acids of this class may be obtained easily.

2. The action of a variety of primary, secondary and tertiary anines on the phthalamidic acids has been investigated.

3. Secondary and tertiary amines, if they are not ton negative, convert the phthalamidic acids, $\mathrm{RNHCOC}_{6} \mathrm{H}_{1}\left(\mathrm{CO}_{2} \mathrm{H}\right.$, into imides, $\mathrm{C}_{8} \mathrm{H}_{4}\left\langle\mathrm{CO}_{\mathrm{CO}}^{\mathrm{CO}}>\mathrm{NR}\right.$

4. Primary amines, $\mathrm{R}^{\prime} \mathrm{NH}_{2}$, give rise to one or more of the following products, $\quad \mathrm{R}^{\prime} \mathrm{NHCOC}_{8} \mathrm{H}_{4} \mathrm{CO}_{2} \mathrm{H}$,<smiles></smiles>

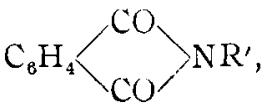
$\mathrm{RNHCOC}_{6} \mathrm{H}_{4} \mathrm{CONHR}^{\prime}$ and $\mathrm{C}_{8} \mathrm{H}_{4}\left(\mathrm{CONHR}^{\prime}\right)_{2}$.

5. The primary step in the action of all the amines consists in the production of salts, a number of which have been prepared.

6. Alcohol (95 per cent.) has a specific influence in favoring the transformation of acid to imide.

7. It is suggested that this behavior is also due to (oxonium) salt formation and that the same conception is applicable to the numerous condensations produced by small quantities of tertiary bases, mineral acids, alkalies, metallic salts etc.

The work on the phthalamidic acids and allied compounds is being extended in various directions in this laboratory by Messrs. Brenton and Bates under the direction of the senior author.

McMaster UNiversity, Toronto, Can,, September, 1908 . 